Digestion 1990;45(suppl 1):88

\title{
Author/Subject Indexes
}

Numbers refer only to this supplement issue

Ainsworth, I. 17 Bax, N.D.S. 17 Bloom, S.R. 5,43 Buchanan, K.D. 11 Burnham, W.R. 77 Chayvialle, J.A. 23 Collins, J.S.A. 11 Farthing, M.J.G. 77, 87 Finnegan, S. 66 Glaser, B. 27 Hopman, W.P.M. 72 Irving, M.H. 66 Jansen, J.B.M.J. 72 Johnston, C.F. 11 Kloppenborg, P.W.C. 72 Lamers, C.B.H.W. 72 Landaw, H. 27 Lennard-Jones, J.E. 77 Liessum, P.A. van 72 McKee, R. 60 Nightingale, J.M.D. 77 Pieters, G.F.F.M. 72 Primrose, J.N. 49 Rosenbusch, G. 72 Scott, N.A. 66 Shaw, C. 11 Smals, A.G.H. 72 Tangerman, A. 72 Varghese, A. 11 Walker, E.R. 77 Woods, H.F. 17 Wynick, D. 5

Abdominal carcinoid tumours 17

Acromegaly 72

Apudomas 11

Carcinoid tumours 23

Cholecystokinin 72

Dumping syndrome 49

Exocrine pancreas 72

Gallbladder 72

Gastrointestinal fistula 66

Hammersmith Hospital 5

High output 77

Hyperinsulinaemic hypoglycaemia of infancy 27

Lyon 23

Octreotide 5, 27, 49, 60, 66, 72, 77

Oesophageal varices 60

Pancreatic islet cell tumours 5

Queen's University of Belfast 11

Samotostatin 77

Sandostatin 5, 11, 17, 23, 27, 49, 60, 66, 72

Sheffield 17

Short bowel syndrome 77 